\title{
Erratum to: Financial statement errors: evidence from the distributional properties of financial statement numbers
}

\author{
Dan Amiram ${ }^{1}$ Zahn Bozanic ${ }^{2} \cdot$ Ethan Rouen $^{1}$
}

\section{Erratum to: Rev Account Stud DOI 10.1007/s11142-015-9333-z}

The author corrections were inadvertently missed in the online published article, which has now been included here:

In page 39 of the online published article, the end point has been missed in the description of Figure 3. It should be "Conformity to Benford's distribution, firm examples.".

In page 49 of the online published article, Score has been wrongly mentioned in Table 8 as a subscript. Also, "i,t" must not be italicized. However, it has been corrected with the erratum.

The online version of the original article can be found under doi:10.1007/s11142-015-9333-z.

\section{Zahn Bozanic}

bozanic.1@fisher.osu.edu

Dan Amiram

da2477@columbia.edu

Ethan Rouen

ethanrouen@columbia.edu

1 Columbia Business School, Columbia University, New York, NY, USA

2 Fisher College of Business, The Ohio State University, Columbus, OH, USA 
Table 8 FSD_Score and restated data

$$
\begin{aligned}
& \text { FSD_Score }_{i, t}=\alpha+\beta_{1} \text { RESTATED_NUMS }_{\mathrm{i}, \mathrm{t}}+\beta_{2} \mathrm{ABS} \_J O N E S \_R E S I D_{\mathrm{i}, \mathrm{t}} \\
& +\beta_{3} \text { STD_DD_RESID }_{\mathrm{i}, \mathrm{t}}+\beta_{4} \text { MANIPULATOR }_{\mathrm{i}, \mathrm{t}}+\beta_{5} \mathrm{~F}_{-} \mathrm{SCORE}_{\mathrm{i}, \mathrm{t}} \\
& +\beta_{6} \mathrm{ABS}_{-} \mathrm{WCACC} \mathrm{i}_{\mathrm{i}, \mathrm{t}}+\beta_{7} \mathrm{ABS} \_\mathrm{RSST} \mathrm{i}_{\mathrm{t}, \mathrm{t}}+\varepsilon_{\mathrm{i}, \mathrm{t}}
\end{aligned}
$$

Variable

FSD_Score

(1) (2)

\begin{tabular}{lll}
\hline RESTATED_NUMS & $-0.0009^{* * *}$ & $-0.0009 * * *$ \\
& $(-5.26)$ & $(-5.33)$ \\
ABS_JONES_RESID & & 0.0000 \\
STD_DD_RESID & & $(0.06)$ \\
& & $0.0049^{* * *}$ \\
MANIPULATOR & $(7.88)$ \\
F_SCORE & $0.0005^{*}$ \\
& & $(1.89)$ \\
ABS_WCACC & & $-0.0033^{* * *}$ \\
& & $(-10.11)$ \\
ABS_RSST & & $0.0024^{*}$ \\
Constant & & $(1.65)$ \\
& & $0.0032^{* * *}$ \\
Observations & $0.0288^{* * *}$ & $(5.66)$ \\
R-squared & $(244.85)$ & $0.0289^{* * *}$ \\
\hline
\end{tabular}

Table 8 examines the relation between Benford's Law and restated data. The OLS regressions use financial statement data from firms that restated their financial statements for the period 2001-2011. We require that firms have both restated and original financial data available in Compustat. RESTATED_NUMS is an indicator that equals 1 for restated numbers and 0 for misstated numbers used in the calculation of FSD_Score. FSD_Score is the mean absolute deviation between the empirical distribution of leading digits contained in a firm's financial statements and Benford's Law. See Appendix 1 for the calculation of FSD_Score. See Appendix 6 for definitions of the control variables. t-statistics are reported in parentheses in the table. $*, * *$, and $* * *$ indicate significance at the $0.10,0.05$, and 0.01 levels, respectively 